\title{
Obtaining a composite material based on cobalt (II) ferrite for purification of aqueous solutions
}

\author{
Nina Shabelskaya ${ }^{1, *}$, Marina Egorova ${ }^{1}$, Galina Chernysheva ${ }^{1}$, and Vladimir Semchenko ${ }^{1}$ \\ ${ }^{1}$ Platov South-Russian State Polytechnic University (NPI), Novocherkassk, Russian Federation
}

\begin{abstract}
In modern society, the detrimental effect of industrial production on the environment is intensifying. Contaminated wastewaters of industrial enterprises deteriorate the environmental situation and violate the ecosystem stability. One of efficient methods of dealing with harmful impurities in wastewater is to remove them using adsorption active materials. Oxide systems of ferrites of transition elements are one example of materials with multifunctional properties. The possibility of synthesizing nanoscale cobalt (II) ferrite and a composite material based on it with the CoFe2O4/C composition was studied. The obtained materials were studied using X-ray phase analysis, electron microscopy (SEM), and the BET method of low-temperature nitrogen adsorption. It was established that cobalt (II) ferrite has a developed surface (the surface area measured by the BET method is $16 \mathrm{~m} 2 / \mathrm{g}$, the average crystallite size obtained by the Debye-Scherrer method is $4.0 \mathrm{~nm}$ ). The mechanism of CoFe2O4 structure formation is considered. The composite material $\mathrm{CoFe} 2 \mathrm{O} 4 / \mathrm{C}$ is characterized by a high surface area $(222 \mathrm{~m} 2 / \mathrm{g}$, average crystallite size of $1.1 \mathrm{~nm}$ ) and exhibits increased adsorption ability with respect to copper (II) cations from aqueous solutions. The obtained results are of interest as materials for purification of aqueous solutions.
\end{abstract}

\section{Introduction}

In modern society, the detrimental effect of industrial production on the environment is intensifying. Contaminated wastewaters of industrial enterprises deteriorate the environmental situation and violate the ecosystem stability. One of efficient methods of dealing with harmful impurities in wastewater is to remove them using adsorption active materials. Oxide systems of ferrites of transition elements, possessing spinelstructure with general formula $\mathrm{MFe}_{2} \mathrm{O}_{4}(\mathrm{M}$ is a bivalent cation) are one example of materials with multifunctional properties. Of particular interest are ferrites-spinels based on cobalt (II) ferrite $\mathrm{CoFe}_{2} \mathrm{O}_{4}$, as these are magnetic materials [1-7], which can be used as electrodes in lithium-ion batteries [8-10], selective sensors [11], absorbants of microvawe radiation [12], adsorbents of metal cations and coloring agents [13-17], catalysts [18-21], for medical purposes in cancer treatment [22]. Despite many years of research of oxide ferrite systems, the interest for such systems is still very strong.

In recent years, the amount of researches on the possibilities of synthesis of nanosized materials with spinel structure has increased [4, 13, 17, 22]. As it is known, nanocrystalline materials possess a number of technically important characteristics in comparison with well crystallized polycrystalline samples. These factors are crucial in the processes associated with adsorption and catalytic reactions occurring on the surface of substances. In this regard, special attention is paid to obtaining samples with developed surfaces. The traditional methods for producing ferrites with spinel structure include ceramic (from oxides of the corresponding metals) [2], decomposition of hydroxides and salts [7]. To obtain fine-crystalline samples, various methods are used, in particular, decomposition of organic component of the reaction mixture, which can be polyvinylpyrrolidone [10, 23], citric [20] or other [24] organic acids, etc. The most significant effect in a number of technical processes is achieved when using composite materials containing both organic and inorganic components [10,12, 21]. The aim of this work was to study the possibility of synthesizing the nanosized composite material $\mathrm{CoFe}_{2} \mathrm{O}_{4} / \mathrm{C}$ and to assess its adsorption activity with respect to copper cations from aqueous solutions.

\section{Methods}

The initial substances for samples preparation were solutions with a concentration of $1.0 \mathrm{~mole} / \mathrm{l}$, composed of $\mathrm{Fe}\left(\mathrm{NO}_{3}\right)_{3} \cdot 9 \mathrm{H}_{2} \mathrm{O}, \mathrm{Co}\left(\mathrm{NO}_{3}\right)_{2} \cdot 7 \mathrm{H}_{2} \mathrm{O}$ of the $\mathrm{CP}$ grade. To prepare cobalt (II) ferrite samples the method described in [25] was used. A typical procedure was as

\footnotetext{
*Corresponding author: nina_shabelskaya@mail.ru
} 
follows: the solution mixture of the ratio of iron (III) nitrate:cobalt (II) nitrate $=2: 1$ was placed in a stainless steel reaction vessel, then $15 \mathrm{ml}$ of the $25 \%$ aqueous ammonia solution was added, then it was mixed with 25 $\mathrm{ml}$ of citric acid solution of 6.25 mole/l concentration, evaporated to obtaining a dry residue and subjected to heat treatment until complete decomposition of the organic component.

For preparing $\mathrm{CoFe}_{2} \mathrm{O}_{4} / \mathrm{C}$ composite material, activated carbon with grain sizes not exceeding $0.5 \mathrm{~mm}$ was placed in a reaction vessel, and the synthesis procedure was carried out in a similar way to that described above.

Phase composition was investigated by diffractometer ARL X'TRA using $\mathrm{Cu}-\mathrm{K} \alpha$ radiation. Refinement of structure of phases included in the samples was carried out by reflexes 220, 311, 222, 422, 333, 440. The samples photos were obtained using scanning electron microscope. The surface area was determined by BET technique using the ChemiSorb 2750 in the Center for Collective Usage "Nanotechnologies" of Platov South-Russian State Polytechnic University (NPI).

The average crystal dimension $D(\mathrm{~nm})$ was calculated by the Debye-Scherrer equation [26] using the line 311:

$$
\left.D=\frac{0.9 \cdot \lambda}{\mathrm{B} \cdot \cos \Theta}\right),
$$

where $\lambda=1.5406 \mathrm{~nm}$ is the wavelength, $B$ is the full peak width at the half-intensity, $\theta$ is the diffraction angle.

The absorption capacity of spinels was studied at room temperature. The adsorption activity of samples was evaluated by sorption of copper (II) cations from solution. A certain amount of sorbent was added to 10 $\mathrm{ml}$ of the model solution and kept for 0.5 - 2 hours, occasionally stirring. The content of copper (II) cations in the test solution was determined by the photocolorimetric method using the KFK-2-UHL 4.2 device. To prepare the sample, the solution of copper (II) sulfate was transferred to the ammonia complex. The degree of purification $(N)$ of the solution from $\mathrm{Cu}^{2+}$ cations was calculated by the formula :

$$
N=\frac{C_{0}-C}{C_{0}} 100 \text {, }
$$

where $C_{0}$ is the initial concentration of coppercations in the solution, $\mathrm{mg} / \mathrm{l} ; C$ is the current concentration, $\mathrm{mg} / \mathrm{l}$.

\section{Results and Discussion}

Samples were prepared according to the sol-gel technique in the presence of an organic template. During sample preparation, when mixing solutions of the initial $\mathrm{Fe}\left(\mathrm{NO}_{3}\right)_{3}$ and $\mathrm{Co}\left(\mathrm{NO}_{3}\right)_{2}$ salts with ammonia solution, the formation of a dark amorphous precipitate was first observed. It should be assumed that formation of transition metal hydroxides proceeds in the system in accordance with the equations:

$\mathrm{Co}\left(\mathrm{NO}_{3}\right)_{2}+2 \mathrm{NH}_{3} \cdot \mathrm{H}_{2} \mathrm{O}=\mathrm{Co}(\mathrm{OH})_{2}+2 \mathrm{NH}_{4} \mathrm{NO}_{3}$,

$\mathrm{Fe}\left(\mathrm{NO}_{3}\right)_{3}+3 \mathrm{NH}_{3} \cdot \mathrm{H}_{2} \mathrm{O}=\mathrm{Fe}(\mathrm{OH})_{3}+3 \mathrm{NH}_{4} \mathrm{NO}_{3}$

As it is known, cobalt (II) hydroxide has from crimson to violet color, depending on the deposition conditions. Iron (III) hydroxide is brownish brown. The intermediate reaction product had a dark color due to overlapping of colors of these hydroxides. It was shown in [27] that, under these conditions, the formation of nanodispersed powders of iron oxides and cobalt (II) ferrite can also occur, which can subsequently act as a nucleus for the formation of the target product. In the system under consideration, the formation of ammonia complexes of transition metals is possible: $\mathrm{Co}(\mathrm{OH})_{2}+4 \mathrm{NH}_{3}=\left[\mathrm{Co}\left(\mathrm{NH}_{3}\right)_{4}\right](\mathrm{OH})_{2}$,

$$
\mathrm{Fe}(\mathrm{OH})_{3}+6 \mathrm{NH}_{3}=\left[\mathrm{Fe}\left(\mathrm{NH}_{3}\right)_{6}\right](\mathrm{OH})_{3} \text {. }
$$

Further the citric acid solution, having the following formula is introduced into the system:

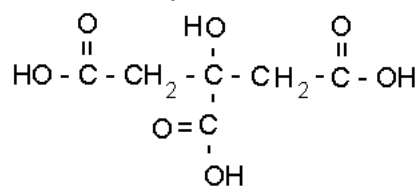

It is accompanied by the process of formation of complex citrates described by the following reactions:

$\left[\mathrm{Co}\left(\mathrm{NH}_{3}\right)_{4}\right](\mathrm{OH})_{2}+\mathrm{C}_{6} \mathrm{H}_{8} \mathrm{O}_{7}=\mathrm{CoC}_{6} \mathrm{H}_{6} \mathrm{O}_{7}+2 \mathrm{H}_{2} \mathrm{O}$

$\left[\mathrm{Fe}\left(\mathrm{NH}_{3}\right)_{6}\right](\mathrm{OH})_{3}+\mathrm{C}_{6} \mathrm{H}_{8} \mathrm{O}_{7}=\mathrm{Fe}\left(\mathrm{C}_{6} \mathrm{H}_{5} \mathrm{O}_{7}\right)+3 \mathrm{H}_{2} \mathrm{O}$.

When citrates, possessing framework structure

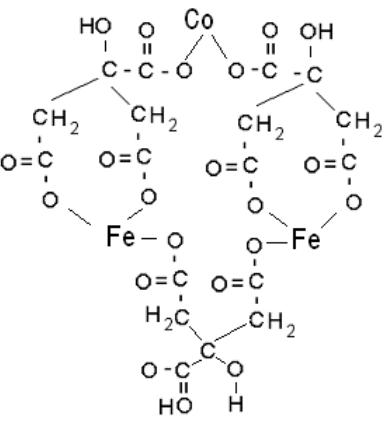
a).

are decomposed, a porous material is formed (Fig. 1,

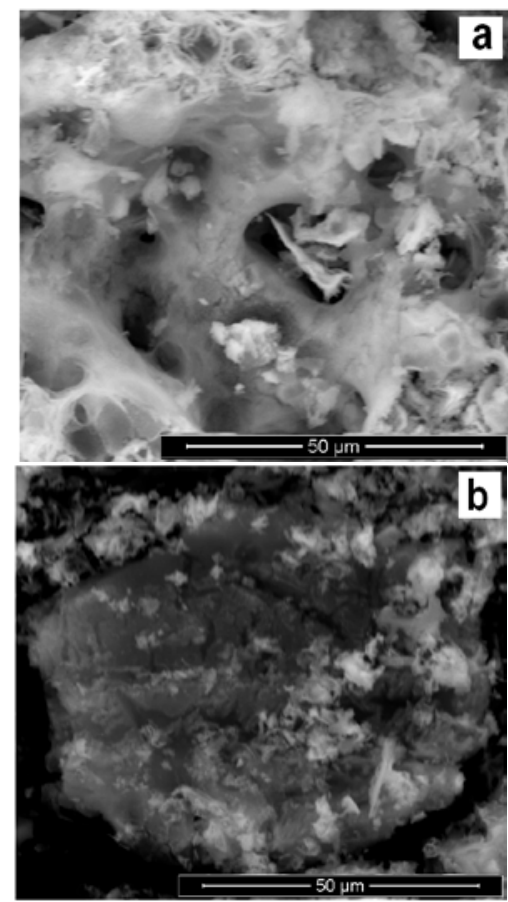

Fig. 1. Microphotographs of the cobalt (II) ferrite (a) and the composite material (b). Magnification x 2000. 
The process ends with the formation of a porous mass. Upon further heating, a black crystalline powder of a cellular structure with pores of large diameter is formed (Fig. 1, a). The specific surface area measured by the BET method is $16 \mathrm{~m}^{2} / \mathrm{g}$. The calculation of the average crystallite size according to the Debye-Scherrer equation for the most intense line gives the result $\mathrm{D}=4.0$ nm.

Synthesis of the $\mathrm{CoFe}_{2} \mathrm{O}_{4} / \mathrm{C}$ composite was carried out similarly to the procedure described above. Activated carbon was placed in the reaction vessel; solutions of salts of transition elements were added. Then solutions of ammonia and citric acid were introduced successively while continuous stirring. The reaction vessel was heated until decomposition of organic precursor. The formation of black samples with a developed surface was observed (Fig. 1, b). The specific surface area measured by the BET method is $222 \mathrm{~m}^{2} / \mathrm{g}$. The crystallite size obtained according to the Debye-Scherrer equation was $\mathrm{D}=1.1$ nm.

X-ray phase analysis (Fig. 2) showed that the sample was cobalt (II) ferrite with the structure of a cubic spinel (Cobalt Iron Oxide PDF Number: 010-79-1744).

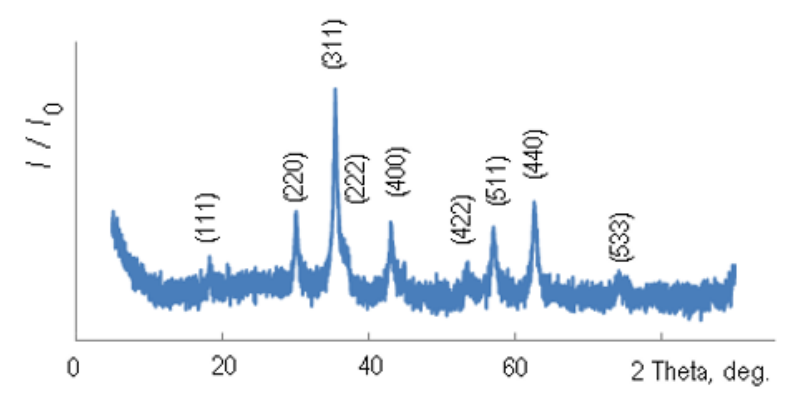

Fig. 2. X-ray diagram of cobalt (II) ferrite.

The crystal lattice constant is $a=0.59366 \mathrm{~nm}$. The carbon carrier is X-ray amorphous. Cobalt (II) ferrite exhibits the properties of a soft magnetic material. In this regard, the obtained composite material $\mathrm{CoFe}_{2} \mathrm{O}_{4} / \mathrm{C}$ combines the properties of a highly porous adsorption material due to the presence of activated carbon and a magnetic material due to $\mathrm{CoFe}_{2} \mathrm{O}_{4}$.

Excessive copper cations in the human body cause toxic effects. This leads to disruption in functioning of the nervous system and internal organs. The problem of treating wastewater containing copper cations is relevant due to the widespread use of copper-containing materials in industry. So, copper compounds are used in the paint and varnish industry, in electrochemical industries, for wood impregnation, and for medical purposes. For the synthesized materials, the adsorption activity of $N$ for absorption of copper (II) cations from aqueous solutions was studied.

For carrying out the experiments, the samples were cut up to the grain sizes of $0.3 \mathrm{~mm}$, placed into the copper (II) sulphate solution of 0.1 mole/l $(16 \mathrm{~g} / \mathrm{l})$ concentration, and kept for $0.5-2.0$ hours, occasionally stirring. Further the solution was separated from the adsorbent and the quantitative examination of the amount of copper cations in the solution was carried out.
For this purpose a complex-formation reaction was carried out according to the scheme:

$$
\mathrm{CuSO}_{4}+2 \mathrm{NH}_{3} \cdot \mathrm{H}_{2} \mathrm{O}=\mathrm{Cu}(\mathrm{OH})_{2}+\left(\mathrm{NH}_{4}\right)_{2} \mathrm{SO}_{4} \text {, }
$$$$
\mathrm{Cu}(\mathrm{OH})_{2}+4 \mathrm{NH}_{3}=\left[\mathrm{Cu}\left(\mathrm{NH}_{3}\right)_{4}\right](\mathrm{OH})_{2} \text {. }
$$

At the first stage, an amorphous precipitate of blue copper (II) hydroxide is formed. In the presence of an aqueous solution of ammonia, violet ammonia complexes of copper are formed. Estimation of the copper cations content was carried out by the photocolorimetric method.

The results of the study are given in table. 1. For comparison, the adsorption activity of activated carbon without introduced cobalt (II) ferrite was studied under similar conditions.

Table 1. Adsorption activity of samples

\begin{tabular}{|c|c|c|c|c|}
\hline \multirow{2}{*}{ No. } & \multirow{2}{*}{ Sample } & \multicolumn{2}{|c|}{$\begin{array}{c}\text { Content of } \mathbf{C u}^{2+} \\
\text { mole/ }\end{array}$} & \multirow{2}{*}{ N, \% } \\
\cline { 3 - 4 } & & $\mathbf{0 . 5} \mathbf{~ h}$ & $\mathbf{2 . 0} \mathbf{~ h}$ & \\
\hline 1 & $\mathrm{CoFe}_{2} \mathrm{O}_{4} / \mathrm{C}$ & 0.070 & 0.057 & 43 \\
\hline 2 & Activated carbon & 0.070 & 0.061 & 39 \\
\hline
\end{tabular}

The obtained results show that the concentration of copper (II) cations in the solution decreased by $39-43 \%$. In this case, the composite material $\mathrm{CoFe}_{2} \mathrm{O}_{4} / \mathrm{C}$ showed increased adsorption activity compared to that of pure activated carbon.

Thus, the synthesis of nanocrystalline cobalt (II) ferrite and the $\mathrm{CoFe}_{2} \mathrm{O}_{4} / \mathrm{C}$ composite material was carried out. The resulting composite material exhibits increased adsorption capacity with respect to copper cations in aqueous solution. The synthesized materials can be used in water treatment processes for purification of solutions.

\section{Conclusions}

1. The processes of formation of nanoscale cobalt (II) ferrite and $\mathrm{CoFe}_{2} \mathrm{O}_{4} / \mathrm{C}$ composite material were studied.

2. A mechanism for the formation of the sample structure is proposed, that includes the stage of formation of complex compounds and their subsequent destruction upon heating. The possibility of obtaining a homogeneous mixture leading to the formation of the framework structure of cobalt (II) ferrite is discussed.

3. The average crystallite sizes were determined by the Debye-Scherrer formula: for cobalt (II) ferrite it is $4 \mathrm{~nm}$, for the composite material it is $1.1 \mathrm{~nm}$.

4. The increased adsorption capacity of the synthesized $\mathrm{CoFe}_{2} \mathrm{O}_{4} / \mathrm{C}$ composite material in the process of absorption of copper cations from an aqueous solution was established. The resulting materials may be of interest as catalysts and adsorbents.

\section{References}

1. K.J. Kim, J. Park Journal of Sol-Gel Science and Technology 92(1), 40 (2019) 
2. J. Venturini, T.B. Wermuth, M.C. Machado, S. Arcaro, A.K. Alves, A. da Cas Viegas, C.P. Bergmann J. of the European Ceramic Society 39 (12), 3442 (2019)

3. Y.Q. Dai, J.M. Dai, X.W. Tang, Z.F. Zi, K.J. Zhang, X.B. Zhu, J. Yang, Y.P. Sun J. of Magnetism and Magnetic Materials 394, 287 (2015)

4. S. Singh, S. Munjal, N. Khare J. of Magnetism and Magnetic Materials 386, 69 (2015)

5. F. Foroughi, S.A. Hassanzadeh-Tabrizi, J. Amighian J. of Magnetism and Magnetic Materials 382, 182 (2015)

6. R. Illa, R. Ješko, R. Silber, O. Životský, K.M. Kutláková, L. Matějová, M. Kolenčík, J. Pištora, J. Hamrle Materials Research Bulletin 117, 96 (2019)

7. V.H. Ojha, K.M. Kant Physica B: Condensed Matter 567, 87 (2019)

8. T. Sener, E. Kayhan, M. Sevim, Ön. Metin J. of Power Sources 288, 36 (2015)

9. X. Liu, N. Wu, C. Cui, P. Zhou, Y. Sun J. of Alloys and Compounds 644, 59 (2015)

10. Y. Li, Y. Meng, M. Xiao, X. Liu, F. Zhu, Y. Zhang J. of Materials Science: Materials in Electronics 30(13), 12659 (2019)

11. H. Abdolmohammad-Zadeh, E. Rahimpour Sensors and Actuators B 209, 496 (2015)

12. M. Zong, Y. Huang, N. Zhang Applied Surface Science 345, 272 (2015)

13. H. Abdolmohammad-Zadeh, E. Rahimpour Analytica Chimica Acta 881, 54 (2015)

14. Y. Zhang, L. Yan, W. Xu, X. Guo, L. Cui, L. Gao, Q. Wei, B. Du J. of Molecular Liquids 191, 18 (2014)

15. M.A. Khan, M.M. Alam, M. Naushad, Z.A. Alothman, M. Kumar, T. Ahamad Chemical Engineering Journal 279, 416 (2015)

16. F. Foroughi, S.A. Hassanzadeh-Tabrizi, J. Amighian, A. Saffar-Teluri Ceramics International 41, 6844 (2015)

17. K. Al Yaqoob, M. Bououdina, M.S. Akhter, B. Al Najar, J.J. Vijaya, Materials Chemistry and Physics 232, 254 (2019)

18. F. Urbain, R. Du, P. Tang, V. Smirnov, T. Andreu, F. Finger, N. Jimenez Divins, J. Llorca, J. Arbiol, A.Cabot, J.R . Morante Applied Catalysis B: Environmental 259, 118055 (2019)

19. Y. Zhao, B. Cao, Z. Lin, X.Su Environmental pollution (Barking, Essex : 1987) 254, 112961 (2019)

20. S. Huang, Y. Xu, M. Xie, H. Xu, M. He, J. Xia, L. Huang, H. Li Colloids and Surfaces A: Physicochem. Eng. Aspects 478, 71 (2015)

21. L. Gan, S. Shang, C. W. M. Yuen, S. Jiang, E. Hu Applied Surface Science 351, 140 (2015)

22. M.S.A. Darwish, H. Kim, H. Lee, C. Ryu, J.Y. Lee, J. Yoon Nanomaterials 9, 8, 1176 (2019)
23. F. Ren, G. Zhu, P. Ren, K. Wang, X. Cui, X. Yan Applied Surface Science 351, 40 (2015)

24. A. Dey, M.K. Purkait J. of Industrial and Engineering Chemistry 24, 181 (2015)

25. Chernyshev V.M., Shabelskaya N.P. Materials Science Forum 870, 118 (2016)

26. Jang. J.S., Hong S.J., Lee J.S. J. of the Korean Phys. Soc 5, 1, 204 (2009)

27. Gopalan E.V., Al-Omari I.A., Malini K.A., Joy P.A., Kumar D.S., Yoshida Y., Anantharaman M.R. J. of Magnetism and Magnetic Mat. 321, 1092 (2009) 